\title{
The Impact of Workplace Gossip on Organizational Cynicism: Insights from the Employment Relationship Perspective
}

\author{
Chien-Chih $\mathrm{Kuo}^{1}$, Chiu-Yi $\mathrm{Lu}^{2}$, and Ting-Kuei Kuo ${ }^{3}$ \\ ${ }^{1}$ National Chengchi University, Department of Psychology, Taipei, Taiwan \\ ${ }^{2}$ Chung Yuan Christian University, Department of Psychology, Taipei, Taiwan \\ ${ }^{3}$ National Taiwan University of Science \& Technology, \\ Graduate Institute of Technology Management, Taipei, Taiwan \\ cckuo@nccu.edu.tw
}

\begin{abstract}
This study examined the effects of workplace negative gossip on organizational cynicism. Moreover, we explored the antecedents of workplace negative gossip based on the employment relationship perspective, tested the relationship between abusive supervision, psychological contract breach and workplace negative gossip. The data were collected from 455 employees in Taiwan. Three major findings manifest in the results. First, workplace negative gossip had a significant predictability for organizational cynicism. Compare to interpersonal-related negative gossip, the effects of task-related negative gossip on organizational cynicism were larger. Secondly, employment relationship (abusive supervision and psychological contract breach) had significant predictability for the employees' workplace negative gossip. Thirdly, we found that employment relationship affects organizational cynicism through its impact on workplace negative gossip. In summary, workplace negative gossip mediates the relationship between employment relationship and organizational cynicism.
\end{abstract}

Keywords: employment relationship, organizational cynicism, workplace negative gossip.

\section{$1 \quad$ Research Background}

Workplace gossip, defined as exchanges of personal information and judgmental opinions about other people while not in their presence (DiFonzo \& Bordia, 2007; Forster, 2004), is frequently observed in workplace (Noon \& Delbridge, 1993). Workplace gossip as part of the social interaction process, can provide employees an escape from work for social immobility. To explore the nature of workplace gossip can improve the understanding of informal communication within organization. In general, managers possess negative attitude towards gossips in work place and make gossips account for distrust among employees and decline of organizational morale (Akande \& Funmilayo, 1994; Baker \& Jones, 1996). Danziger (1988) considered that gossips have negative impacts in work place resulting in decreasing moral value, uncomfortable personal interactions, and damaging organization reputation. 
The dysfunction of workplace gossip may attribute to its negative attributes (Burke $\&$ Wise, 2003). Negative gossip in workplace refers to the information received is other's bad news such as superior complaint, divorce, affair, or laziness of work. The content of negative gossip generates hostile work climate and implies the person in gossip of poor interpersonal relationship. Furthermore, having thought that it is likely for employees to suffer becoming the focal person in a negative gossip, their attachment to the organization will diminish gradually. Scholars tend to agree that there is more negative gossip in an organization, the more likely the individuals in this organization lose his or her organizational identification. When the cognition, interaction and affection toward the organization become negative and isolated, the organizational cynicism will be generated.

Kurland and Pelled (2000) categorized gossips into task-related and interpersonalrelated. Task-related gossips focus on individual's work such as job performance, career development and interaction with others in workplace. Fiske and Taylor (1991) found that exchange of task-related gossips like compensation package, promotion, performance appraisal in workplace is more attractive and attentive to others compared with general gossips like plastic surgery and divorce. Accordingly, the influences are also different.

This study considers that the degree of negative gossip related to work will influence organizational cynicism. If gossip is task related, it belongs to instrumental ties (Grosser et al., 2010). Instrumental tie originates from the degree of job accomplishment and function deployment, identifying responsibilities of individuals or groups. It defines how work group and work class interacts. Kueland and Pelled (2000) proposed that task-related gossip can form expert power and reference power. Negative task-related gossip will make employees feel less professional. If the gossip is not task related, it belongs to expressive ties. Expressive ties originate from socioemotional component. Social gossips such as divorce, having an affair, selling house, and illness are irrelevant to the role and responsibility that the organization assign. These can be seen as an expression of life but work. It is a way to relieve pressure from work. Interpersonal support and friendship may be obtained through these kinds of interaction and sharing gossips.

Dealing with negative gossip information, worker may consider every gossip has its own motivation and objective. This thought makes workers believe that the organization is strategically calculative and will betray integrity to achieve its goal. The organization will fail to meet worker's expectation. Due to the negative attribution for disappointment, negative emotion and behavior may occur as organizational cynicism. Particularly, when an individual receive task-related negative gossip, he or she may follow the clues to learn about the norm and regulation of the organization. These situational information can contribute to content validity and criterion-related validity, enhancing organizational cynicism. When an individual receive interpersonal-related negative gossip, he or she will take as an expression of emotion for work and like. This does not influence organizational cynicism. 
Hypothesis 1 Task-related negative gossip has positive association with organizational cynicism. Interpersonal-related negative gossip has no significant influence on organizational cynicism.

Prior research indicated that if the employment relationship is not healthy, employee tends to show more attitudes against the organization such as intent to quit (Geurts et al., 1999). Hui, Lee, and Rousseau (2004) proposed two categories of employment relationship. One is employee-organization relationship. This can be described by psychological contract by Schein (1980). If employee believes in organization to keep promise, job security and promotion for example, employees will work hard and maintain loyalty as an exchange or reward. In the contrast, if employees perceive the organization intends to compromise, fail to meet individual expectation, or loss of justice, psychological contract breach may happen. Due to the negative attribution, worker gives special attention to negative gossip in organization. In particular, when facing task-related negative gossip, individual will use selective perception to verify the unfair treatment and feelings.

\section{Hypothesis 2 Psychological contract breach is positively associated with nega- tive task-related gossips but has no association with interpersonal- related gossips.}

Employee-supervisor relationship is another category of employment relationship. Supervisor can be considered as the agency of organization, executing managing duties. Supervisors may humiliate employees in public just because they do not have appropriate personal characteristics and management skills. This kind of unfriendly management style usually contributes to an inferior relationship. Here we refer this as abusive supervision. When facing abusive supervision, employees may feel unfair, anxious, and nervous. They will seek emotional and psychological recovery. Therefore, according to social-information processing theory and self-fulfilling prophecy perspective, regardless of negative task-related or social gossips, employees can use them to justify the perceived inappropriate treatment and improve their perception on negative task-related and interpersonal-related gossips.

Hypothesis 3 Abusive supervision is positively associated with negative gossips (both task-related and interpersonal-related) in workplace.

Under poor employment relationship, either organization or supervisor can induce employees' negative attitudes. Employees will increase the tendency to participate in gossiping by social comparison in order to recover the negative emotion from poor employee-organization relationship. It is more likely to involve negative gossips, particularly task-related ones. Therefore, workers who perceived poor employment relationship will pay extra attention to negative gossips in workplace and generalize the information based on their own experience. They may consider others having the negative attitudes in the poor employment relationship as the same as they do. To have this thought can recover one's injustice feeling and negative emotions, but it 
will reinforce the negative attitude toward organization, leading to organizational cynicism.

Hypothesis 4 Workplace negative gossips can mediate employee-organization relationship (psychological contract breach and abusive supervision) and cynicism.

\section{Methodology}

\subsection{Sample and Procedures}

We tested the hypotheses with data collected at two points in time. At time 1, surveys were distributed to 580 employees in several organizations in Taiwan. We assessed perceptions of workplace negative gossip, psychological contract breach, abusive leadership and demographic variables. At time 2, one month after time 1 data collection, we assessed organizational cynicism. 402 participants who completed the time1 and time 2 surveys, 65 percent were female and 40 percent had marriage. The majority (67 percent) of the participants were within the $25-40$ years age bracket.

\section{$2.2 \quad$ Measures}

Workplace negative gossip. We assessed task-related negative gossip $(\alpha=.89)$ and interpersonal-related negative gossip $(\alpha=.83)$ with measures developed by Kuo (2012). Twelve items assessed the perception of task-related negative gossip and six items assessed the perception of interpersonal-related negative gossip. Illustrative items are 'decrease the items of benefits', 'unfair system of performance appraisal' (task-related negative gossip), 'the poor quality of family life' and 'the traffic accident nearby' (interpersonal-related negative gossip). Participants rated their level of agreement with the items using a scale ranging from 1, not at all, to 6, a great deal.

Psychological contract breach. Psychological contract breach was assessed using a 9-item scale adapted from Robinson and Morrison (2000). This scale measures participants' overall evaluation of the extent to which the organization has fulfilled or breached its obligations to them. The example item is 'Almost all the promises made by my employer during recruitment have been kept so far'. The internal reliability of the scale was .92 .

Abusive supervision. We used Tepper's (2000) 15-item scales $(\alpha=.90)$ to measure participants' perceptions of abusive supervisory behaviors. This measure asks participants to rate the extent to which they agree or disagree with statements such as 'My boss is rude to me' and 'tells me my thoughts and feelings are stupid' on a 6-point scale $(1=$ 'I cannot remember him/her ever using this behavior with me, $5=$ 'He/she uses this behavior every often with me').

Organizational cynicism. We used Kuo's (2000) 8-item scales $(\alpha=.89)$ to measure participants' perceptions of cynicism about one's workplace. This measure asks participants to rate the extent to which they agree or disagree with statements such as 
'I believe that my company lacks integrity' on a 6-point scale ( $1=$ 'strongly disagree, $6=$ 'strongly agree').

\section{Results}

\subsection{Measurement Model}

We assessed responses to the survey items using maximum likelihood confirmatory factor analysis (CFA) to examine the distinctness of the variables. The measurement model consisted of five factors: psychological contract breach, abusive supervision, task-related negative gossip, interpersonal-related negative gossip, and organizational cynicism. The results indicated that the five-factor model provided a good fit to the data, $\chi^{2}(1070)=3,647.30, p<.001$, RMSEA $=.08$, SRMR $=.07$, NFI $=.91$, CFI $=$ .93 , IFI = .93 (Hughes, Price, \& Marrs, 1986). We compared the five-factor model to (a) a four-factor model (where psychological contract breach and abusive supervision were combined into a single 'negative employment relationship' factor), $\chi^{2}(1074)=$ $5,989.50, p<.001, \mathrm{RMSEA}=.11, \mathrm{SRMR}=.09, \mathrm{NFI}=.87, \mathrm{CFI}=.90, \mathrm{IFI}=.90$, (b) a four-factor model (where task-related negative gossip and interpersonal-related negative gossip were combined into a single 'negative gossip' factor), $\chi^{2}(1074)=$ $4,130.67, p<.001, \mathrm{RMSEA}=.09, \mathrm{SRMR}=.07, \mathrm{NFI}=.90, \mathrm{CFI}=.93, \mathrm{IFI}=.93$, (c) a three-factor model (where psychological contract breach and abusive supervision were combined into a single 'negative employment relationship' factor, psychological contract breach and abusive supervision were combined into a single 'negative employment relationship' factor), $\chi^{2}(1077)=6,442.81, p<.001$, RMSEA $=.12$, SRMR $=.09, \mathrm{NFI}=.86, \mathrm{CFI}=.89$, IFI $=.89$, (d) a single-factor model, $\chi^{2}(1080)=$ $15,545.57, p<.001, \mathrm{RMSEA}=.19, \mathrm{SRMR}=.15, \mathrm{NFI}=.79, \mathrm{CFI}=.81, \mathrm{IFI}=.81$.

The five-factor model produced a significant improvement in chi-squares over the four-factor model, $\Delta \chi^{2}(4)=2,342.20, p<.001$, and $\Delta \chi^{2}(4)=483.37, p<.001$; threefactor model, $\Delta \chi^{2}(7)=2,795.51, p<.001$; single-factor model, $\Delta \chi^{2}(10)=11,898.27$, $p<.001$, suggesting a better fit than the other models (Schumacker \& Lomax, 1996).

\subsection{Structural Model}

Psychological contract breach, abusive supervision and task-related negative gossip were all significantly correlated with organizational cynicism; psychological contract breach and abusive supervision were significantly correlated with task-related negative gossip and interpersonal-related negative gossip. The correlation of task-related negative gossip with interpersonal-related negative gossip is $.54(p<.001)$.

The proposed theoretical model exhibited good fit with the data. Even though the chi-square statistic was significant, $\chi^{2}(83)=305.66, p<.001$, the ratio of chi-square to degrees of freedom was approximately equal to 4 , indicated a good fit (Hughes et al., 1986). The other fit indices also indicated good fit between the proposed model and the data (RMSEA $=.09$, SRMR $=.07$, NFI $=.94$, CFI $=.95$, IFI $=.95)$. Other than two paths (psychological contract breach to interpersonal-related negative gossip and interpersonal-related negative gossip to organizational cynicism), all paths in the 
model were significant and in the expected direction. Hypotheses 1, 2, and 3were supported. Psychological contract breach $(\beta=.20)$ was positively related to taskrelated negative gossip. Abusive supervision $(\beta=.26 ; \beta=.27)$ was positively related to task-related negative gossip and interpersonal-related negative gossip. Task-related negative gossip $(\beta=.45)$ was positively related to organizational cynicism.

We performed the test of Hypotheses 4, the mediating role of negative gossip, by analyzing several alternative models. In each alternative model, a direct path was added from psychological contract breach and abusive supervision to organizational cynicism. Based on the chi-square difference, changes in fit indices, and path significance, we compared the alternative models against the proposed theoretical model. The direct path from psychological contract breach to organizational cynicism was significant and resulted in significant improvement in model fit. Abusive supervision had no significant direct impact on organizational cynicism. Hence, task-related negative gossip partially mediated the relationship of psychological contract breach and organizational cynicism, and fully mediated the relationship of abusive supervision and organizational cynicism. Therefore, Hypotheses 4 was partially supported.

\section{Discussion}

Previous research has established that workplace negative gossip can produce a number of dysfunctional consequences. However, the results of this study showed that task-related negative gossip and interpersonal-related negative gossip had the differential effects on organizational cynicism. In other words, not all workplace negative gossip has harmful effects in formal organization. It is clear that the relationship of workplace negative gossip with organizational cynicism emerged for task-related negative gossip but not for interpersonal-related negative gossip. Employees who perceived higher level of task-related negative gossip reported greater organizational cynicism. However, interpersonal-related negative gossip is not related to organizational cynicism. These results extend a growing body of evidence that suggests the various gossip attributes, such as positive vs negative, or task-related vs interpersonalrelated, may play different roles in organization (Akande \& Funmilayo, 1994; Burke \& Wise, 2003; Danziger, 1988).

We found that psychological contract breach and abusive supervision were related to task-related negative gossip, but only abusive supervision was related to interpersonal-related negative gossip. Overall, our results suggest that task-related negative gossip mediated the relationship between two types of employment relationship and organizational cynicism, but interpersonal-related negative gossip had not the mediation effect. It indicates that employees' relationship with their supervisors or employers influenced their perception of the workplace negative gossip, especially task-related gossip, in turn influenced the job attitude. Therefore, the potential harm associated with negative employment relationship ought to serve as a warning to organization. It is important for managers and employers to have a proper appreciation of the nature and dynamics of the psychological contract breach and abusive supervision, and its impact on employee behavior and attitudes. 


\section{References}

1. Akande, A., Funmilayo, O.: One more time- how to stop company rumours. Leadership and Organisation Development Journal 15(4), 27-30 (1994)

2. Baker, J.S., Jones, M.A.: The poison grapevine: How destructive are gossip and rumor in the workplace? Human Resource Development Quarterly 7(1), 75-86 (1996)

3. Burke, L.A., Wise, J.M.: The effective care, handling, and pruning of the office grapevine. Business Horizons 46(3), 71-76 (2003)

4. Danziger, E.: Minimize office gossip. Personnel Journal 67, 31-34 (1988)

5. Dean Jr., J.W., Brandes, P., Dhwardkar, R.: Organizational cynicism. Academy of Management Review 23, 341-352 (1998)

6. DiFonzo, N., Bordia, P.: Rumor psychology: Social and organizational approaches. American Psychological Association, Washington, D.C. (2007)

7. Fiske, S.T., Taylor, S.E.: Social cognition, 2nd edn. McGraw Hill, New York (1991)

8. Foster, E.K.: Research on gossip: Taxonomy, methods and future directions. Review of General Psychology 8, 78-99 (2004)

9. Geurts, S.A., Schaufeli, W.B., Rutte, C.G.: Absenteeism, turnover intention and inequity in the employment relationship. Work \& Stress: An International Journal of Work, Health \& Organization 13(3), 253-267 (1999)

10. Grasser, T., Kidwell-Lopez, V., Labianca, G.: A social network analysis of positive and negative gossip in organizational Life. Group \& Organizations Management 35(2), 177-214 (2010)

11. Hui, C., Lee, C., Rousseau, D.M.: Employment relationships in China: Do workers relate to the organizations or to people? Organization Science 15(2), 232-240 (2004)

12. Johnson, J.L., O'Leary-Kelly, A.M.: The effects of psychological contract breach and organizational cynicism: not all social exchange violations are created equal. Journal of Organisational Behavior 24, 627-647 (2003)

13. Kurland, N.B., Pelled, L.H.: Passing the word: Toward a model of gossip and power in the workplace. Academy of Management Review 25, 428-438 (2000)

14. Noon, M., Delbridge, R.: News from behind my hand: Gossip in organizations. Organization Studies 14, 23-36 (1993)

15. Robinson, S.L., Morrison, E.W.: The development of psychological contract breach and violation: A longitudinal study. Journal of Organizational Behavior 21, 525-546 (2000)

16. Tepper, B.J.: Consequences of abusive supervision. Academy of Management Journal 43(2), 178-190 (2000)

17. Schein, E.H.: Organizational Psychology. Prentice Hall, Englewood Cliffs (1965) 